\title{
The Relationship between Medication Adherence to the Incidence of Failure of First-Line Antiretroviral Therapy (ARV) in HIV/AIDS Patients in Haji Adam Malik Hospital
}

\author{
Mars Evianta $^{1}$, Tambar Kembaren ${ }^{2}$, Lenni Evalina Sihotang ${ }^{2}$, Putri C Eyanoer ${ }^{3}$ \\ ${ }^{1}$ Department of Internal Medicine, Faculty of Medicine, Universitas Sumatera Utara, Medan, Indonesia \\ ${ }^{2}$ Division of Infectious and Tropical Medicine, Department of Internal Medicine, Faculty of Medicine, \\ Universitas Sumatera Utara, Medan, Indonesia \\ ${ }^{3}$ Department of Community and Preventive Medicine, Faculty of Medicine, Universitas Sumatera Utara, Medan, \\ Indonesia \\ Corresponding Author: Mars Evianta
}

DOI: https://doi.org/10.52403/ijrr.20220188

\begin{abstract}
Introduction: Acquired Immunodeficiency Syndrome (AIDS) is a compilation of symptoms or diseases caused by decreased immunity due to infection with Human Immunodeficiency Virus (HIV). The number of HIV and AIDS cases continued to increase until 2019, United Nations Program on HIV and AIDS (UNAIDS) reported that HIV and AIDS cases worldwide had reached around 37.8 million with the highest number of cases found in Africa. Based on the latest report of the Directorate General of P2P (HIV/AIDS and STI Information System (SIHA) in 2019, for the last eleven years, HIV cases in Indonesia reached a peak in 2019, which was 50,282 cases. ARV is the most successful HIV treatment that consists of a combination of several types of drugs that must be taken for life, therefore high compliance is required $(>95 \%)$ and each patient must take medication according to the prescribed dose and time.

Methods: This study was a cross-sectional study, the population has taken in the VCT Unit/center of Haji Adam Malik Hospital, the patients who experienced failure of first-line therapy from February to June 2021. With a total sample of 96 people. Data collection techniques were carried out using a questionnaire sheet.
\end{abstract}

Results: There was a significant relationship between PLWHA who failed first-line therapy on drug side effects ( $p$-value $=0.05$ ) and there was no significant relationship found between knowledge level and adherence to ARV medication $(p$-value $=0.182)$.

Conclusion: Factors that influence adherence to taking PLWHA medication at Haji Adam Malik Hospital Medan, such as level of knowledge and drug regimen, motivation, family support, support from health workers, side effects of drugs.

Keywords: HIV/AIDS; ARV; First Line; PLWHA

\section{INTRODUCTION}

Acquired Immunodeficiency Syndrome (AIDS) is a collection of symptoms or diseases caused by decreased immunity due to infection with the Human Immunodeficiency Virus (HIV). AIDS can be said to be the final stage of HIV infection. The test to check for antibodies to HIV by ELISA was only available in 1985 . A few years later or to be precise in 1987 , the first case of HIV in Indonesia was found in Bali. ${ }^{1}$

HIV is a retrovirus that infects cells of the human immune system, especially CD4 $\mathrm{T}$ cells and macrophages which are vital components of the immune system. This is what makes people with HIV / AIDS 
(PLWHA) have a weak immune system and are susceptible to infection. Therefore, a person must take antiretroviral drugs (ARV) to maintain his immunity. Due to decreased immunity, people with HIV infection and AIDS are very susceptible to various infectious diseases (opportunistic infections) which are often fatal. Patients with HIV infection require antiretroviral (ARV) treatment to reduce the amount of HIV in the body so that it does not enter the AIDS stage, while people with AIDS require antiretroviral (ARV) treatment to prevent opportunistic infections with various complications.

One route of transmission of HIV/AIDS is through unsafe sex with an HIV-infected partner. Risky sex is sex that carries the risk of disease transmission or unplanned pregnancy. Report of the United Nations AIDS Agency or UNAIDS, which states that more than 1.7 million women in ASIA are living with HIV positive, and $90 \%$ of them are infected by their husbands or sexual partners. ${ }^{2,3}$

HIV can be transmitted through the exchange of various body fluids from an infected person, such as blood, breast milk, semen, and vaginal fluids. HIV can also be passed from a mother to her child during pregnancy and childbirth. People cannot be infected through everyday contacts such as kissing, hugging, shaking hands, or sharing personal objects, food, or water. ${ }^{4}$

The World Health Organization (WHO) reports that in 2013 there were 35 million people in the world living with HIV and AIDS. In 2015 there were 2.1 million (1.8 million-2.4 million) new HIV infections worldwide, adding to a total of 36.7 million (34.0 million-39.8 million) people living with HIV. The number of sufferers increased from the end of 2014, there were around 34,300,000-41.4 million people with HIV and 2 million $(1,900,000-$ 2,200,000) people were infected with HIV and 1.2 million $(980,000-1,600,000)$ people died. due to AIDS-related illnesses. The number of HIV and AIDS cases continued to increase until 2019, the United Nations
Program on HIV and AIDS (UNAIDS) reported that HIV and AIDS cases worldwide had reached around 37.8 million with the highest number of cases found in Africa (25.7 million cases). ${ }^{2.5}$

Although it tends to fluctuate, data on HIV AIDS cases in Indonesia continues to increase from year to year. HIV and AIDS cases have spread to 386 districts/cities in all provinces in Indonesia. The cumulative number of HIV sufferers from 1987 to September 2014 was 150,296 people, while the cumulative total of AIDS cases was 55,779 people. Based on the latest report of the Directorate General of P2P (HIV/AIDS and STI Information System (SIHA) in 2019, for the last eleven years, the number of HIV cases in Indonesia reached its peak in 2019, which was 50,282 cases. $^{2,6}$

Although there is no cure yet that can kill the virus that causes AIDS, current treatments are aimed at increasing hope and quality of life. This treatment is done by giving a combination of ARVs that aim to stop the activity of the virus, restore the immune system and reduce the occurrence of opportunistic infections, improve quality of life and reduce disability. ARV also does not cure HIV patients but can improve the quality of life and extend the life expectancy of HIV/AIDS patients. ARVs are the most successful HIV treatment to date. ARV drugs consist of a combination of several types of drugs that must be taken for life, therefore high compliance is required $(>95 \%)$ and each patient must take medication according to the prescribed dose and time.

Based on data in the world in 2017 , it was found that $59 \%$ of all people living with HIV accessed treatment with details; $59 \%$ of adults aged 15 years living with HIV have access to treatment, and $52 \%$ of children aged $0-14$ years. In addition, $65 \%$ of adult women aged 15 years have access to care, only $53 \%$ of adult men aged 15 years and older have access. In 2017 it was also found that $80 \%$ of pregnant women living with HIV have access to antiretroviral 
drugs to prevent HIV transmission to their babies. The number of people living with HIV/AIDS (PLWHA) who receive ARV nationally has not reached $10 \%$ of the total estimated number of PLWHA in Indonesia, it is estimated that there are 591,823 PLWHA, while those who have been and are receiving ARV treatment are 39,418 PLWHA. However, unfortunately only about half of people living with HIV/AIDS were receiving antiretroviral therapy at the end of 2016, this treatment has promising success rates. To be able to provide optimal therapeutic results, the use of these drugs must be carried out with some strict requirements. Some of these things are the use of the right combination, patient compliance, and being aware of unwanted effects due to drug interactions. ${ }^{7,9}$

Currently, more than 400 health services are available throughout Indonesia. ARV is divided into two lines. First-line or first line consists of a combination of nucleoside reverse transcriptase inhibitors (NRTIs) including Zidovudine (AZT) or Tenofovir (TDF) with Lamivudine (3TC) or Emtricitabine (FTC), as well as nonnucleoside reverse transcriptase inhibitors (NNRTI) including Nevirapine (NVP) or Efavirenz (EFV). Meanwhile, line 2 consists of an NRTI, as well as a ritonavir-boosted protease inhibitor (PI), namely Lopinavir/Ritonavir. Line 1 itself consists of a combination of 2 NRTIs and 1 NNRTI, while line 2 consists of a combination of 2 NRTIs and 1 PI. ${ }^{7,9}$

Treatment in HIV patients was declared successful based on three things: clinical success (clinical changes occurred in HIV patients such as weight gain or improvement in opportunistic infections); immunological success (there was a change in the CD4 lymphocyte count towards improvement, which was higher than the initial treatment); and virological efficacy (reducing the amount of virus in the blood, as low as possible or below the detection limit known as the undetectable viral load). ${ }^{10}$
In Indonesia, several studies have stated that the biggest barriers to HIV services with access to antiretroviral drugs (ARVs) are influenced by geographic factors and the availability of funds. Although, ARV has been made free by the Ministry of Health since 2006. However, this condition does not directly reduce the number of deaths from HIV-AIDS cases, due to barriers to access to ARV drugs by people living with HIV-AIDS (PLWHA), and the crucial problem is the money must be issued to obtain HIV services. ${ }^{11}$

In its development, ARV drugs can be made cheaper and affordable in the form of generic drugs with similar quality and quality and provide opportunities as an effort in national medicine. On the other hand, it was found cases of dropping out of treatment for HIV-AIDS patients related to treatment-seeking behavior. ${ }^{12}$

Virological failure is an early indicator of treatment failure of a single combination ARV drug. After a virological failure occurs, with time it will be followed by immunological failure and finally, clinical failure will occur which is characterized by the re-emergence of opportunistic infections. This is due to the low number of CD4 lymphocytes due to viral resistance to the antiretroviral drugs being used. Virologic failure occurs earlier than immunologic and clinical failure. Therefore, viral load testing will detect treatment failure earlier and more accurately than monitoring using immunological or clinical criteria, thereby preventing increased morbidity and mortality of HIV patients. Viral load testing is also used to estimate the risk of transmission to others, especially among pregnant women living with HIV and at the population level. HIV patients who fail first-line treatment must use second-line ARV treatment to achieve ARV treatment goals. ${ }^{13}$

Adherence is a major factor in achieving the successful treatment of HIV infection. Compliance is taking medication according to the dose, never forgetting, on time, and never break. Compliance with 
taking ARV is the most important factor in suppressing the amount of HIV in the human body. The long and stable suppression of the number of viruses aims to keep the body's immune system high. Thus, people infected with HIV will get a good quality of life and also prevent illness and death. ${ }^{14}$

In the study by Koole et al on the research of Debby, et al, there were four main obstacles in increasing ARV adherence, including the following: (1) individual patient factors (age, gender, education level, knowledge, medication); (2) family support factor; (3) treatment factor therapy regimen; and (4) supporting factors, namely health insurance. For the research method, Debby, et al. conducted interviews with several patients at the HIV UPT of RSUPN DR Cipto Mangunkusumo, it was found that they often did not take ARV drugs because they forgot and had passed the time to take medicine, were bored, and busy at work. Whereas adherence to taking ARV drugs is influenced by the existence of factors that are important in determining the success of therapy. In addition, adherence to taking ARV drugs in Indonesia itself has not been widely studied. ${ }^{15}$

Based on this background, the researchers were interested in examining the relationship between adherence to the incidence of failure of first-line antiretroviral therapy (ARV) in HIV/AIDS patients at Haji Adam Malik Hospital, Medan.

\section{MATERIALS \& METHODS}

The research design used in this study was cross-sectional, the population was taken in the VCT Unit / Pusyansus Room at Haji Adam Malik Hospital, Medan, namely patients who experienced first-line therapy failure from February to June 2021. The determination of the sample in this study was carried out by using the consecutive sampling method, with a total sample of 96 people. Inclusion criteria in this study: HIV/AIDS patients aged over 18 years, a confirmed diagnosis of HIV infection according to the procedures from the Indonesian Ministry of Health, had taken second-line ARVs due to failed therapy and were willing to participate in the study. The exclusion criteria in this study were: the patient did not undergo a complete laboratory examination, and the subject withdrew/refused to continue the research process. Data collection techniques were carried out using a questionnaire sheet. To determine the level of compliance of patients with first-line therapy failure, the questionnaire method is expected to produce a conclusion, what factors are associated with treatment failure and how much influence the level of adherence to first-line therapy failure has.

Subjects who met the inclusion and exclusion criteria were explained and asked to provide written informed consent to participate in the study. Data in the form of age, gender, ethnicity, occupation, and education level of the participants were obtained from medical records or anamnesis. Patients were then asked to fill out a questionnaire, to measure viral load before and after receiving first-line ARV therapy and to measure CD4 cell values by checking existing laboratory data.

\section{Statistical Analysis}

Data analysis was performed using the Statistical Package for the Social Sciences (SPSS) 24.0 software. Numerical variables were presented as mean and standard deviation if normally distributed, moreover presented as median (minimummaximum value) when not normally distributed. Categorical variables were presented as percentages.

\section{RESULT}

Characteristics of respondents in the categories of Gender, Age, Education, Employment and Marital Status of patients with HIV/AIDS (PLWHA) at the Center Poli of Haji Adam Malik Hospital Medan. The proportion of PLWHA in the male sex is 61 people $(63.5 \%)$, this number is more 
Mars Evianta et.al. The relationship between medication adherence to the incidence of failure of first-line antiretroviral therapy (ARV) in HIV/AIDS patients in Haji Adam Malik Hospital.

than the proportion of PLWHA with female gender, which is 35 people $(36.5 \%)$. The proportion of PLWHA who failed therapy, the majority in the age group > 30 years were 77 people $(80.2 \%)$, most of the PLWHA with the latest D3 education were 25 people $(26.0 \%)$ and followed by the number of PLWHA with the last education at SD there were 23 people $(24,0 \%)$, the majority of people living with HIV who experience therapy failure are self-employed (51.0\%), and 72 people (75\%) (Table 1).

Table 1. Distribution of Characteristics of PLWHA Respondents at Haji Adam Malik Hospital Medan

\begin{tabular}{|l|l|l|}
\hline Characteristics & Number of people (n) & Percentage (\%) \\
\hline Gender & & \\
\hline Man & 61 & 63.5 \\
\hline Woman & 35 & 36.5 \\
\hline Age & & \\
\hline$<30$ years old & 19 & 19.8 \\
\hline$>$ 30 Years & 77 & 80.2 \\
\hline Education & & \\
\hline SD & 23 & 24.0 \\
\hline junior high school & 21 & 21.9 \\
\hline senior High School & 22 & 22.9 \\
\hline D3 & 25 & 26.0 \\
\hline S1 & 5 & 5.2 \\
\hline Work & & \\
\hline civil servant & 9 & 9.4 \\
\hline Private employee & 38 & 39.6 \\
\hline entrepreneur & 49 & 51.0 \\
\hline Marital Status & & \\
\hline Marry & 72 & 75.0 \\
\hline Not married yet & 24 & 25.0 \\
\hline Total & $\mathbf{9 6}$ & $\mathbf{1 0 0 . 0}$ \\
\hline
\end{tabular}

PLWHA with good knowledge level is 32 people $(33.3 \%)$, adequate knowledge level is 36 people $(37.5 \%)$, less knowledge level is 28 people (29.2\%), the majority of PLWHA who experience therapy failure have medication adherence sufficient. The table shows that there are 67 people $(69.8 \%)$ of 96 respondents with poor motivation. The proportion of people living with HIV who experience therapy failure has high family support, there are 83 people $(86.5 \%)$. For the support factor of health workers, the proportion of PLWHA who experienced therapy failure received high support as many as 75 people (78.1\%), for the side effect factor of PLWHA drugs who experienced treatment failure the majority experienced severe drug side effects as many as 63 people $(65.6 \%)$ (Table 2).
Table 2. Frequency Distribution of Factors Affecting Adherence to ARV Therapy

\begin{tabular}{|l|l|l|}
\hline Factors & $\begin{array}{l}\text { Number of people } \\
\text { (n) }\end{array}$ & $\begin{array}{l}\text { Percentage } \\
(\%)\end{array}$ \\
\hline Knowledge level & & \\
\hline Good & 32 & 33.3 \\
\hline Enough & 36 & 37.5 \\
\hline Not enough & 28 & 29.2 \\
\hline Motivation & & \\
\hline Good & 29 & 30.2 \\
\hline Bad & 67 & 69.8 \\
\hline Family support & & \\
\hline Tall & 83 & 86.5 \\
\hline Low & 13 & 13.5 \\
\hline $\begin{array}{l}\text { Support Health } \\
\text { Workers }\end{array}$ & & \\
\hline Tall & 75 & 78.1 \\
\hline Low & 21 & 21.9 \\
\hline Drug Side Effects & & \\
\hline Light & 33 & 34.4 \\
\hline Heavy & 63 & 65.6 \\
\hline Total & $\mathbf{9 6}$ & $\mathbf{1 0 0 . 0}$ \\
\hline
\end{tabular}

Compliance is the patient's involvement in self-healing, either through compliance with the instructions given for therapy or obedience to carry out or carry out other recommendations in support of therapy. The results of the study showed that 8 people were living with HIV $(8.3 \%)$ who experienced therapy failure, 39 people (40.6\%), and 49 people with a low level of adherence 49 people with moderate adherence. 0\%). Based on the data above, most people living with HIV who experience therapy failure are with low adherence (Table 3).

Table 3. Distribution of adherence to taking ARV drugs

\begin{tabular}{|l|l|l|}
\hline ARV Therapy Adherence & Frequency & Percentage \\
\hline Tall & 8 & $8.3 \%$ \\
\hline Currently & 39 & $40.6 \%$ \\
\hline Low & 49 & $51.0 \%$ \\
\hline Total & 96 & $100.0 \%$ \\
\hline
\end{tabular}

PLWHA failed first-line therapy with good knowledge level there were 32 people with high adherence there were 2 people $(6 \%)$ moderate adherence there were 15 people $(47 \%)$ and low adherence there were 15 people (47\%). PLWHA knowledge is sufficient there are 36 people with high adherence there is 1 person (2.8\%) with moderate compliance there are 13 people (36.1\%) and PLWHA with low compliance there are 22 people $(61.1 \%)$, while the level of knowledge is less known there are 49 people with high compliance there are 5 people $(18 \%)$ moderate compliance there 
Mars Evianta et.al. The relationship between medication adherence to the incidence of failure of first-line antiretroviral therapy (ARV) in HIV/AIDS patients in Haji Adam Malik Hospital.

are 11 people $(39 \%)$ and low compliance there are 12 people $(43 \%)$. With a p-value $=$ 0.182 , there was no significant relationship between knowledge level and adherence to ARV medication (Table 4).

\begin{tabular}{|c|c|c|c|c|c|c|c|c|c|}
\hline \multirow[t]{3}{*}{ Knowledge level } & \multicolumn{8}{|c|}{ Medication Compliance } & \multirow[t]{2}{*}{ P-Value } \\
\hline & \multicolumn{2}{|c|}{ Tall } & \multicolumn{2}{|c|}{ Currently } & \multicolumn{2}{|c|}{ Low } & \multicolumn{2}{|c|}{ TOTAL } & \\
\hline & $\mathbf{n}$ & $\%$ & $\mathbf{n}$ & $\%$ & $\mathbf{n}$ & $\%$ & $\mathbf{n}$ & $\%$ & 0.182 \\
\hline Good & 2 & $6, \%$ & 15 & $47 \%$ & 15 & $47 \%$ & 32 & $100 \%$ & \\
\hline Enough & 1 & $2.8 \%$ & 13 & $36.1 \%$ & 22 & $61.1 \%$ & 36 & $100 \%$ & \\
\hline Not enough & 5 & $18 \%$ & 11 & $39 \%$ & 12 & $43 \%$ & 28 & $100 \%$ & \\
\hline
\end{tabular}

PLWHA failed first-line therapy with good motivation there were 29 people with high adherence there were 2 people (7\%) moderate adherence there were 12 people $(41.3 \%)$ and low adherence were 15 people $(51.7 \%) .67$ people are living with HIV with poor motivation with high adherence there are 6 people $(9 \%)$ with moderate compliance there are 27 people $(40.3 \%)$ and low adherence there are 34 people $(50.7 \%)$. With a p-value $=0.945$ on the motivation factor, it was found that there was no significant relationship between PLWHA who failed first-line therapy (Table 5).

Table 5. The Relationship of Motivation to Adherence to Taking Drugs

\begin{tabular}{|c|c|c|c|c|c|c|c|c|c|}
\hline \multirow{3}{*}{ Motivation } & \multicolumn{8}{|c|}{ Medication Compliance } & \multirow{2}{*}{ P-Value } \\
\hline & \multicolumn{2}{|c|}{ Tall } & \multicolumn{2}{|c|}{ Currently } & \multicolumn{2}{|c|}{ Low } & \multicolumn{2}{|c|}{ TOTAL } & \\
\hline & $\mathbf{n}$ & $\%$ & $\mathbf{n}$ & $\%$ & $\mathbf{n}$ & $\%$ & $\mathbf{n}$ & $\%$ & 0.945 \\
\hline Good & 2 & $7 \%$ & 12 & $41.3 \%$ & 15 & $51.7 \%$ & 29 & $100 \%$ & \\
\hline $\mathrm{Bad}$ & 6 & $9 \%$ & 27 & $40.3 \%$ & 34 & $50.7 \%$ & 67 & $100 \%$ & \\
\hline
\end{tabular}

PLWHA with high family support failed first-line therapy there were 83 people with high adherence there was 6 people (7.2\%) moderate adherence there were 35 people $(42.2 \%)$ and low adherence there were 42 people $(50.6 \%)$. PLWHA with low adherence there are 13 people with high adherence there are 2 people $(15.4 \%)$ with moderate adherence there are 4 people $(30.8 \%)$ and low adherence there are 7 people $(53.8 \%)$. With a $\mathrm{p}$-value $=0.527$ on the family support factor, it was found that there was an insignificant relationship between family support for PLWHA who failed first-line therapy (Table 6).

Table 6. Relationship of Family Support to Compliance with Medication

\begin{tabular}{|c|c|c|c|c|c|c|c|c|c|}
\hline \multirow{3}{*}{ Family support } & \multicolumn{8}{|c|}{ Medication Compliance } & \multirow[t]{2}{*}{ P-Value } \\
\hline & \multicolumn{2}{|c|}{ Tall } & \multicolumn{2}{|c|}{ Currently } & \multicolumn{2}{|c|}{ Low } & \multicolumn{2}{|c|}{ TOTAL } & \\
\hline & $\mathbf{n}$ & $\%$ & $\mathbf{n}$ & $\%$ & $\mathbf{n}$ & $\%$ & $\mathbf{n}$ & $\%$ & 0.527 \\
\hline Tall & 6 & $7.2 \%$ & 35 & $42.2 \%$ & 42 & $50.6 \%$ & 83 & $100 \%$ & \\
\hline Low & 2 & $15.4 \%$ & 4 & $30.8 \%$ & 7 & $53.8 \%$ & 13 & $100 \%$ & \\
\hline
\end{tabular}

PLWHA with high support from health workers failed first-line therapy there were 71 people with high adherence there were 5 people $(6.6 \%)$ moderate adherence was 32 people $(42.7 \%)$ and low adherence was 38 people $(50.7 \%)$. PLWHA with low support from health workers there are 21 people with high adherence there are 3 people $(14.3 \%)$ with moderate adherence there are 7 people $(33.3 \%)$ and low adherence there are 11 people $(52.4 \%)$. With a p-value $=0.471$ on the support factor for health workers, it was found that there was an insignificant relationship with PLWHA who failed first-line therapy (Table 7).

Table 7. The Relationship of Health Workers' Support to Medication Compliance

\begin{tabular}{|c|c|c|c|c|c|c|c|c|c|}
\hline \multirow{3}{*}{ Health Worker Support } & \multicolumn{8}{|c|}{ Medication Compliance } & \multirow[t]{2}{*}{ pValue } \\
\hline & \multicolumn{2}{|c|}{ Tall } & \multicolumn{2}{|c|}{ Currently } & \multicolumn{2}{|c|}{ Low } & \multicolumn{2}{|c|}{ TOTAL } & \\
\hline & $\mathbf{n}$ & $\%$ & $\mathbf{n}$ & $\%$ & $\mathbf{n}$ & $\%$ & $\mathbf{n}$ & $\%$ & 0.471 \\
\hline Tall & 5 & $6.6 \%$ & 32 & $42.7 \%$ & 38 & $50.7 \%$ & 75 & $100 \%$ & \\
\hline Low & 3 & $14.3 \%$ & 7 & 33307 & 19 & 5991 & 2 & $100 \%$ & \\
\hline
\end{tabular}


PLWHA failed first-line therapy with mild drug side effects there were 33 people with high adherence there were 5 people $(15.2 \%)$ moderate adherence there were 16 people $(48.4 \%)$ and low adherence there were 12 people (36.4\%). 63 people were living with HIV with severe drug side effects with high adherence, there were 3 people $(4.8 \%)$ with moderate adherence there were 23 people $(36.5 \%)$ and 37 people had low adherence $(58.7 \%)$. With p-value $=$ 0.05 ( $p<0.05)$. In terms of drug side effects, there was a significant relationship between PLWHA and failure of first-line therapy (Table 8).

Table 8. The Relationship of Drug Side Effects to Drug Compliance

\begin{tabular}{|c|c|c|c|c|c|c|c|c|c|}
\hline \multirow[t]{3}{*}{ Drug Side Effects } & \multicolumn{8}{|c|}{ Medication Compliance } & \multirow[t]{2}{*}{ pValue } \\
\hline & \multicolumn{2}{|c|}{ Tall } & \multicolumn{2}{|c|}{ Currently } & \multicolumn{2}{|c|}{ Low } & \multicolumn{2}{|c|}{ TOTAL } & \\
\hline & $\mathbf{n}$ & $\%$ & $\mathbf{n}$ & $\%$ & $\mathbf{n}$ & $\%$ & $\mathbf{n}$ & $\%$ & 0.05 \\
\hline Light & 5 & $15.2 \%$ & 16 & $48.4 \%$ & 12 & $36.4 \%$ & 33 & $100 \%$ & \\
\hline Heavy & 3 & $4.8 \%$ & 23 & $36.5 \%$ & 37 & $58.7 \%$ & 63 & $100 \%$ & \\
\hline
\end{tabular}

\section{DISCUSSION}

\section{Relationship between Knowledge Level and Drug Compliance}

According to Lawrence Green (1980) regarding behavioral theory on predisposing factors, understanding of a person's health is influenced, among others, by knowledge to increase awareness of the individual's health.

The results of this study, there was no relationship between the level of knowledge and adherence to taking medication with $\mathrm{p}=0.182$ ( $\mathrm{p}>0.05$ ). medication adherence, because in this study a questionnaire about the level of knowledge did not include knowledge about medication adherence, and medication adherence itself was measured by a different questionnaire.

The results of this study are in line with the research of Sunaryo et al who got a $\mathrm{p}$-value $=0.78$ on the relationship of knowledge to compliance behavior in 2017 and Suryani and Jafar's research in 2011. That there is no effect of knowledge on compliance behavior, although according to Sunaryo and Suryani's research, knowledge is a part of the behavioral domain but does not guarantee that individuals with sufficient knowledge have the same behavior.

\section{Relationship between motivation and adherence to taking ARV drugs}

The results of research by Anggipita Budi Mahardining, Semarang State
University in 2010 with 22 samples showed that the largest percentage of respondents had a high motivation of $68.2 \%$, namely 15 people. Based on fisher's exact statistical test, $\mathrm{p}$-value $=0.007(\mathrm{p}<0.05)$ with a $95 \%$ confidence level indicates that $\mathrm{Ho}$ is rejected, which means that there is a significant relationship between motivation to take medication and adherence to ARV therapy.

Meanwhile, the results of this study showed that there was no significant relationship between motivation and medication adherence. Although the results of the study showed that there was no relationship between motivation and adherence to medication, the majority of PLWHA who experienced therapy failure in this study had poor motivation with a low level of adherence, the number of respondents with poor motivation who had low medication adherence was 67 people $(69,8 \%)$ with $\mathrm{p}=0.945$ ( $\mathrm{p}>0.05)$.

\section{Relationship between Health Worker Support and Compliance with taking ARV drugs}

The results of this study indicate that there is no significant relationship between the support of health workers and medication adherence. Although there is no relationship in statistical tests, PLWHA who experience therapy failure get support from health workers, the majority of whom are high 75 people out of 96 respondents, but the level of adherence to taking medication 
is still low, this can happen because PLWHA who receive therapy at the Pusyansus Poli has the intensity of meetings. and consultations with health workers are still low, in this case, the example of taking medicine to the hospital is often represented by the Drug Taking Supervisor (PMO) and the interval of recontrol at the Poly is usually every 30 days.

This result is reinforced by the theory of Soekidjo Notoadmojo (1997) who says that behavior is an activity of the human itself and is divided into two, namely passive and active. In this study, the respondents were in the passive category.

This study is in line with the 2017 research by Alce Apri Feranita Suki, et al., which showed that 39 people with leprosy felt the role of health workers in helping patients comply in taking medication (91\%) and who did not feel the role of health workers in helping patients compliance in taking medication. as many as 4 people $(9 \%)$. Based on the results of statistical tests, showing $\mathrm{p}=1,000$ or $\mathrm{p}>0.05$ so it can be stated that there is no effect between the role of health workers and adherence to taking medication for leprosy patients. In the study, Alce et al. also obtained literacy that the results of the study were more due to the role of health workers being studied leading to a role in providing additional information, not the role of health workers in motivating patients to recover.

\section{Relationship of Family Support to adherence to taking ARV drugs}

This study found that there was a low adherence to medication as many as 42 people who received support from a high family, a significant value of $\mathrm{p}=0.527$ ( $p>0.05)$, there was no relationship between family support and adherence to taking ARV drugs. Researchers assume that the support that patients get from their families tends to be negative so it affects the patient's fear but not adherence to taking ARV drugs.

Friedman (1998) said that people live in a supportive environment, their condition is much better than those who do not have an unsupportive environment.

This study is in line with Mari Ulfah in 2011, showing that poor family support in non-adherent patients has a greater percentage $(21.9 \%)$ than good family support (19.4\%) but does not have a significant difference. Based on the chi test square $\mathrm{p}$ value $=1.00(\mathrm{p}>0.05)$, which means that there is no significant relationship between family support and adherence to TB medication.

\section{The Relationship of Drug Side Effects on Compliance with Taking Medication}

In the study of the relationship of drug side effects, it showed adherence to ARV therapy to drug side effects of respondents at Haji Adam Malik Hospital, where respondents' compliance was high on side effects of good drugs by 5 people $(5.2 \%)$ and high compliance of respondents with side effects of bad drugs was 3 people (3.1\%) while the respondents' compliance with Medium to Good Drug Side Effects was 16 people (16.7\%) and moderate respondent's compliance with Bad Drug Side Effects was 23 people (20.4\%), respondents' compliance was Low on Side Effects There are 12 good drugs (12.5\%) and low respondent compliance on the Side Effects of Bad Drugs there are 37 people (38.5\%) from the study obtained a value of 0.05 where the $\mathrm{p}$-Value value of $0.05<0.05$ can be concluded there is a relationship which is significant on ARV therapy adherence to family support of patients with HIV/AIDS at Haji Adam Malik General Hospital Medan.

The results of this study are following the results of Sasmita aji's Herlambang research which showed that $38.6 \%$ of respondents had no side effects, while $61.4 \%$ had side effects. It is known that 46 respondents with the $\mathrm{ZDV}+3 \mathrm{TC}+\mathrm{NVP}$ regimen experienced the most side effects (37\%) nausea, $32.6 \%$ vomiting, $26.1 \%$ dizziness and itching, $17.4 \%$ drowsiness, $8.7 \%$ skin rash, $6.5 \%$ diarrhea, and others. $2.2 \%$ each experienced 
decreased appetite, forgetfulness, allergies, and muscle pain. Patients reported experiencing these side effects between 1 to 6 weeks at the start of therapy. It is known that of the 20 respondents with the $\mathrm{ZDV}+3 \mathrm{TC}+\mathrm{EFV}$ regimen experiencing the most side effects $(30 \%)$ headache, then nausea, itching, drowsiness $25 \%$ each, $15 \%$ diarrhea, while those who experience vomiting, allergies, and nightmares each have each is $10 \%$. And others have difficulty sleeping is $5 \%$. Patients report experiencing these side effects between 1 to 4 weeks at the start of therapy. Of the two respondents with the d4T $30+3 \mathrm{TC}+\mathrm{NVP}$ therapy regimen, both experienced side effects of nausea and vomiting, while a person experienced drowsiness, diarrhea, and vomiting (50\%). These side effects are felt by the patient for an average of 1 week. The 2 respondents with the combination therapy regimen $\mathrm{d} 4 \mathrm{~T} 30+3 \mathrm{TC}+\mathrm{EFV}$ and the combination therapy regimen $\mathrm{d} 4 \mathrm{~T} 40+$ $3 \mathrm{TC}+$ NVP did not experience side effects. Based on the results of statistical analysis with Chi-Square obtained p-value $=0.005$. Because the $p$-value $<0.005$, it can be stated that there is a significant relationship between the experience of side effects and adherence to ARV therapy.

Patients report experiencing these side effects between 1 to 4 weeks at the start of therapy. Of the two respondents with the $\mathrm{d} 4 \mathrm{~T} 30+3 \mathrm{TC}+\mathrm{NVP}$ therapy regimen, both experienced side effects of nausea and vomiting, while a person experienced drowsiness, diarrhea, and vomiting (50\%). These side effects are felt by the patient for an average of 1 week. The 2 respondents with the combination therapy regimen $\mathrm{d} 4 \mathrm{~T}$ $30+3 \mathrm{TC}+\mathrm{EFV}$ and the combination therapy regimen $\mathrm{d} 4 \mathrm{~T} 40+3 \mathrm{TC}+\mathrm{NVP}$ did not experience side effects. Based on the results of statistical analysis with ChiSquare obtained $\mathrm{p}$-value $=0.005$. Because the $p$-value $<0.005$, it can be stated that there is a significant relationship between the experience of side effects and adherence to ARV therapy. Patients report experiencing these side effects between 1 to
4 weeks at the start of therapy. Of the two respondents with the d4T $30+3 \mathrm{TC}+\mathrm{NVP}$ therapy regimen, both experienced side effects of nausea and vomiting, while a person experienced drowsiness, diarrhea, and vomiting $(50 \%)$. These side effects are felt by the patient for an average of 1 week. The respondents with the combination therapy regimen $\mathrm{d} 4 \mathrm{~T} 30+3 \mathrm{TC}+\mathrm{EFV}$ and the combination therapy regimen $\mathrm{d} 4 \mathrm{~T} 40+$ $3 \mathrm{TC}+$ NVP did not experience side effects. Based on the results of statistical analysis with Chi-Square obtained p-value $=0.005$. Because the $p$-value $<0.005$, it can be stated that there is a significant relationship between the experience of side effects and adherence to ARV therapy. while drowsiness, diarrhea, and vomiting were experienced by a person (50\%). These side effects are felt by the patient for an average of 1 week. The respondents with the combination therapy regimen $\mathrm{d} 4 \mathrm{~T} 30+3 \mathrm{TC}$ $+\mathrm{EFV}$ and the combination therapy regimen $\mathrm{d} 4 \mathrm{~T} 40+3 \mathrm{TC}+\mathrm{NVP}$ did not experience side effects. Based on the results of statistical analysis with Chi-Square obtained $\mathrm{p}$-value $=0.005$. Because the $\mathrm{p}$-value < 0.005 , it can be stated that there is a significant relationship between the experience of side effects and adherence to ARV therapy. while drowsiness, diarrhea, and vomiting were experienced by 1 person $(50 \%)$. These side effects are felt by the patient for an average of 1 week. The respondents with the combination therapy regimen $\mathrm{d} 4 \mathrm{~T} 30+3 \mathrm{TC}+\mathrm{EFV}$ and the combination therapy regimen $\mathrm{d} 4 \mathrm{~T} 40+3 \mathrm{TC}$ + NVP did not experience side effects.

Based on the results of statistical analysis with Chi-Square obtained $\mathrm{p}$-value $=$ 0.005 . Because the $\mathrm{p}$-value $<0.005$, it can be stated that there is a significant relationship between the experience of side effects and adherence to ARV therapy. Based on the results of statistical analysis with Chi-Square obtained p-value $=0.005$. Because the p-value $<0.005$, it can be stated that there is a significant relationship between the experience of side effects and adherence to ARV therapy. Based on the 
Mars Evianta et.al. The relationship between medication adherence to the incidence of failure of first-line antiretroviral therapy (ARV) in HIV/AIDS patients in Haji Adam Malik Hospital.

results of statistical analysis with ChiSquare obtained $\mathrm{p}$-value $=0.005$. Because the $\mathrm{p}$-value $<0.005$, it can be stated that there is a significant relationship between the experience of side effects and adherence to ARV therapy.

\section{CONCLUSION}

The proportion of patients who failed ARV therapy at Haji Adam Malik Hospital Medan, namely a large number of samples in this study compared to the total number of HIV/AIDS patients who received ARV therapy at Haji Adam Malik Hospital:

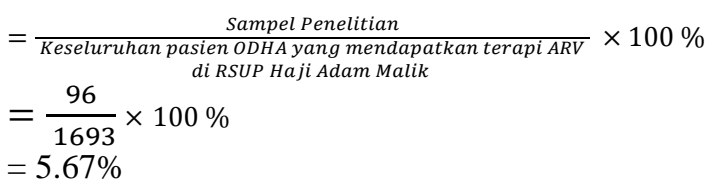

So based on the above calculation, the proportion of PLWHA who failed firstline ARV therapy was $5.67 \%$, thus resistance testing was not needed. However, if the proportion value is above $10 \%$, the resistance test can be investigated.

The proportion of adherence to taking PLWHA medication who failed firstline therapy at Haji Adam Malik Hospital Medan, namely:

- Compliance with taking medication is high: $8.4 \%$ or as many as 8 people

- Adherence to taking medication is: $40.6 \%$ or as many as 39 people

- Compliance with taking medication is low: $51.0 \%$ or as many as 49 people

Factors that influence adherence to taking PLWHA medication at Haji Adam Malik Hospital Medan, namely: level of knowledge and drug regimen, motivation, family support, support from health workers, side effects of drugs. In drug side effects there is a significant relationship with medication adherence. Low respondent compliance there are 37 people $(38.5 \%)$ with a $\mathrm{p}$-value $=0.05(\mathrm{p}$-value 0.05$)$ can be concluded.

Acknowledgement: None

Conflict of Interest: None
Source of Funding: None

Ethical Approval: Approved

\section{REFERENCES}

1. US Fauci. Human immunodeficiency virus disease: AIDS and related diseases. Harrison's Internal Medicine. 2008:1137204.

2. Indonesian Ministry of Health. HIV AIDS Situation and Analysis. Jakarta: Data and Information Center. 2014.

3. Green CW. HIV, Pregnancy and Woman Health: Foundation. 2005.

4. World Health Organization. HIV updates, Global Summary Web. World Health Organization, 2019.

5. UNAIDS Global Statistics. In WA Day. UNAIDS. 2015

6. Indonesian Ministry of Health. Information on HIV/AIDS situation and analysis. Health data and information center (InfoDATIN) Ministry of Health. 2019.

7. Yuliandra Y, Nosa US, Raveinal, Almeisdy D. Antiretroviral Therapy in HIV/AIDS Patients in RSUP. Dr. M. Djamil Padang: Sociodemographic Studies and Drug Evaluation. Journal of Pharmaceutical \& Clinical Science, 2017; 4(1): 1-8

8. Harison N, Waluyo A, and Jumaiyah W. Understanding of antiretroviral treatment and barriers to adherence to antiretroviral therapy in HIV/AIDS patients. Journal of Health of Studies. 2020; 4(1): 87-95. Doi: 10.31101/jhes. 1008

9. UNAIDS. Global HIV \& AIDS statistics 2018 fact sheet. 2018. http://www.unaids.org/en/resources/fact

10. Indonesian Minister of Health. National Action Plan for HIV-AIDS Control 20152019. Jakarta: Indonesian Ministry of Health; 2015.

11. Riyarto S, Hidayat B, Johns B, Probandari A, Mahendradhata $Y$ et al. 2010. The financial burden of HIV care, including antiretroviral therapy, on patients in three sites in Indonesia. Oxford University Press, Health Policy and Planning 2010;25:272282.

12. Susana, R. Treatment seeking behavior towards sexually transmitted infections and HIV-AIDS among female street sex workers in Jayapura City. Gadjah Mada University: Thesis. 2007. 
Mars Evianta et.al. The relationship between medication adherence to the incidence of failure of first-line antiretroviral therapy (ARV) in HIV/AIDS patients in Haji Adam Malik Hospital.

13. Miller WC, Powers KA, Smith MK, Cohen MS. Community viral load as a measure for the assessment of HIV treatment as prevention. Lancet Infected Dis. 2013;13: 459-64.

14. Kurniawan F, et al. Predictors of Virological Failure in HIV Patients Receiving First-Line ARV Therapy with Good Medication Adherence. Indonesian Journal of Internal Medicine. 2017; 4(1): 29 - 34.

15. Debby C, Sianturi SR, Susilo WH. Factors Related to Compliance of ARV Medication in HIV Patients at RSCM Jakarta. J Nursing. 2019;10(1):16.

How to cite this article: Mars Evianta, Tambar Kembaren, Lenni Evalina Sihotang et.al. The relationship between medication adherence to the incidence of failure of first-line antiretroviral therapy (ARV) in HIV/AIDS patients in Haji Adam Malik Hospital. International Journal of Research and Review. 2022; 9(1): 760-770. DOI: https://doi.org/10.52403/ijrr.20220188 